\title{
Corrigendum: An Ethylene-Protected Achilles' Heel of Etiolated Seedlings for Arthropod Deterrence
}

\section{OPEN ACCESS}

Approved by:

Frontiers in Plant Science,

Frontiers Media SA, Switzerland

*Correspondence:

Steffen Reinbothe sreinbot@ujf-grenoble.fr

Sachin Rustgi

rustgi@wsu.edu:

srustgi@clemson.edu

${ }^{\dagger}$ Present Address:

Edouard Boex-Fontvieille, Laboratoire de Biotechnologies Végétales Appliquées aux Plantes Aromatiques et Médicinales, FRE CNRS3727, Université Jean Monnet,

10 Rue Tréfilerie, Saint-Étienne, France

Specialty section: This article was submitted to

Plant Physiology,

a section of the journal

Frontiers in Plant Science

Received: 27 October 2018 Accepted: 08 November 2018 Published: 07 December 2018

Citation:

Boex-Fontvieille E, Rustgi S, von Wettstein D, Pollmann S, Reinbothe $S$ and Reinbothe $C$ (2018) Corrigendum: An Ethylene-Protected Achilles' Heel of Etiolated Seedlings for Arthropod Deterrence. Front. Plant Sci. 9:1741. doi: 10.3389/fp/s.2018.01741

\author{
Edouard Boex-Fontvieille ${ }^{1 \dagger}$, Sachin Rustgi ${ }^{2,3 *}$, Diter von Wettstein ${ }^{3}$, Stephan Pollmann ${ }^{4}$, \\ Steffen Reinbothe ${ }^{1 *}$ and Christiane Reinbothe ${ }^{1}$ \\ ${ }^{1}$ Laboratoire de Génétique Moléculaire des Plantes and Biologie Environnementale et Systémique, Université Grenoble-Alpes \\ - Laboratoire de Bioénergétique Fondamentale et Appliquée, Grenoble, France, ${ }^{2}$ Department of Agricultural and \\ Environmental Sciences-Pee Dee Research and Education Center, Clemson University, Florence, SC, United States, \\ ${ }^{3}$ Department of Crop and Soil Sciences - Center for Reproductive Biology, School of Molecular Biosciences, Washington \\ State University, Pullman, WA, United States, ${ }^{4}$ Centro de Biotecnología y Genómica de Plantas, Univerdidad Politécnica de \\ Madrid - Instituto Nacional de Investigación y Tecnología Agraria y Alimentación, Madrid, Spain
}

Keywords: skotomorphogenesis, apical hook, Arabidopsis thaliana, protease inhibitor action, herbivore deterrence

\section{A Corrigendum on}

An Ethylene-Protected Achilles' Heel of Etiolated Seedlings for Arthropod Deterrence by Boex-Fontvieille, E., Rustgi, S., von Wettstein, D., Pollmann, S., Reinbothe, S., and Reinbothe, C. (2016). Front. Plant Sci. 7:1246. doi: 10.3389/fpls.2016.01246

In the original article, there was a mistake in Figure 5 Expression of NTT and HEC1 versus Kunity-PI;1 transcripts in response to phytohormones, as published. Due to a technical error, the same image was shown twice in the lowermost panel of Figure 5C (Ponceau stains) for the hecl and 35S:: hec1 lines. The original Ponceau stain as well as corrected Figure 5 Expression of NTT and HEC1 versus Kunity-PI;1 transcripts in response to phytohormones, appears below. The authors apologize for this error and state that this does not change the scientific conclusions of the article in any way. The original article has been updated.

Conflict of Interest Statement: The authors declare that the research was conducted in the absence of any commercial or financial relationships that could be construed as a potential conflict of interest.

Copyright (c) 2018 Boex-Fontvieille, Rustgi, von Wettstein, Pollmann, Reinbothe and Reinbothe. This is an open-access article distributed under the terms of the Creative Commons Attribution License (CC BY). The use, distribution or reproduction in other forums is permitted, provided the original author(s) and the copyright owner(s) are credited and that the original publication in this journal is cited, in accordance with accepted academic practice. No use, distribution or reproduction is permitted which does not comply with these terms. 


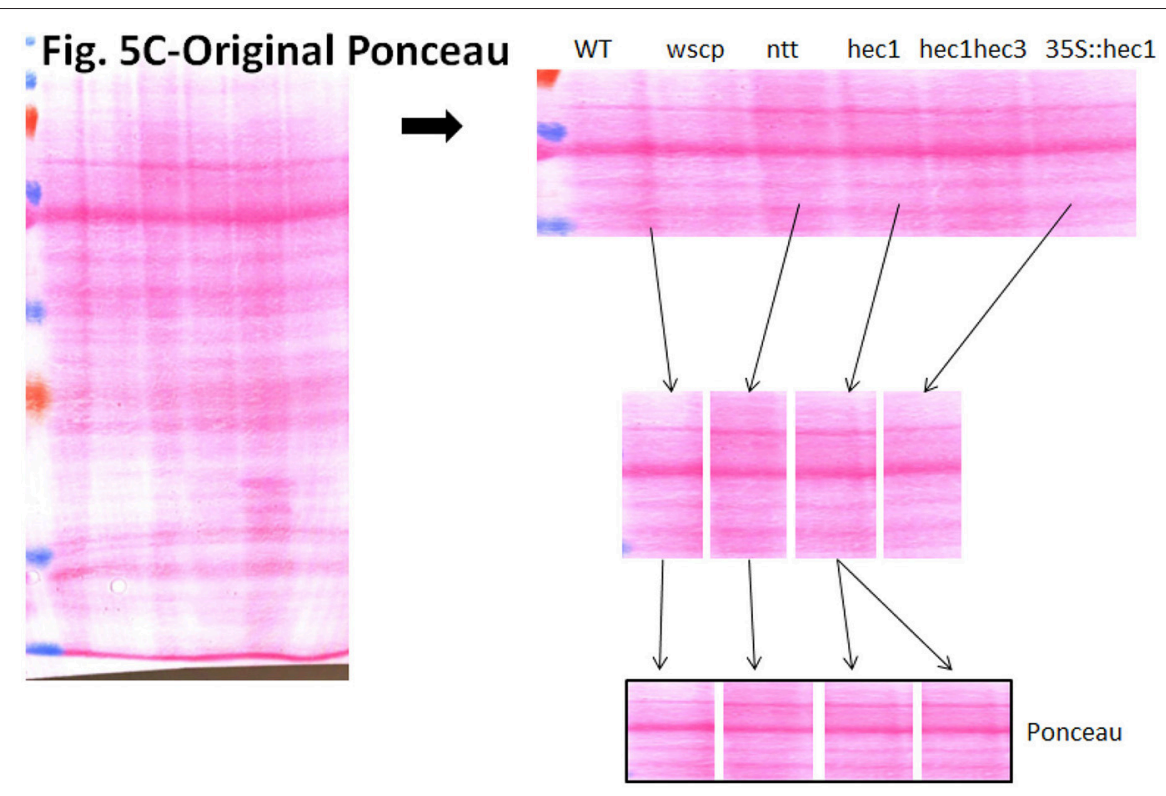

Fig. 5-corrected

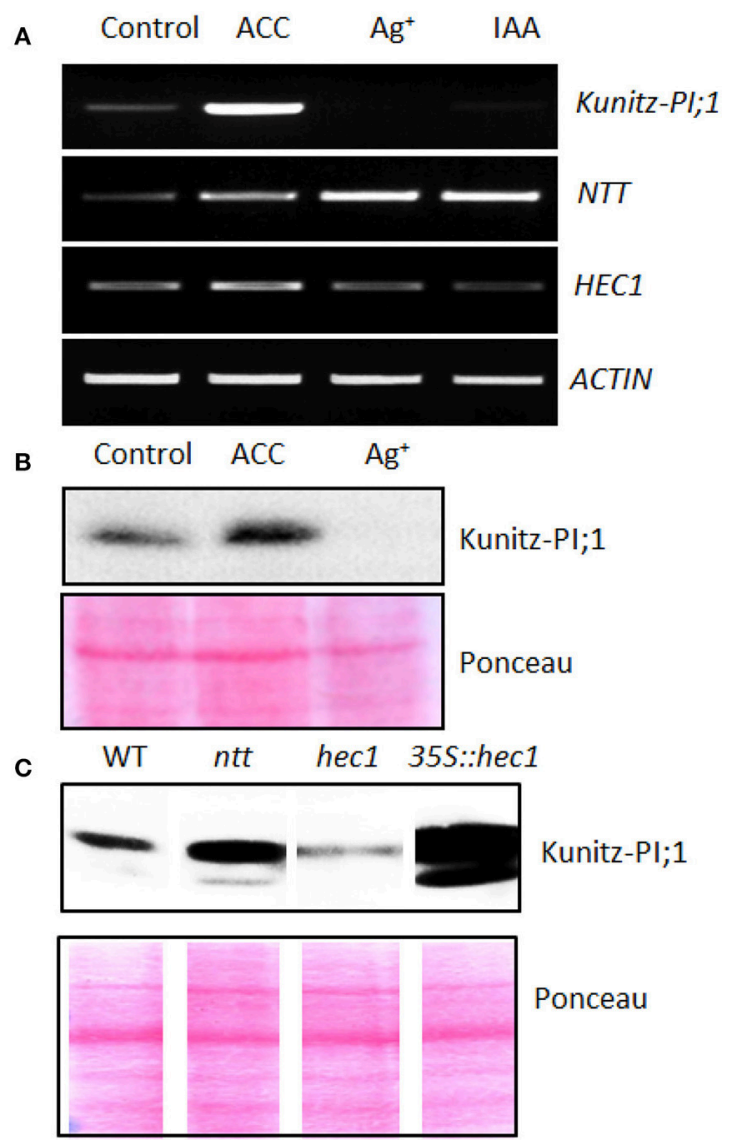

FIGURE 5 | Expression of NTT and HEC1 versus Kunity-Pl;1 transcripts in response to phytohormones. (A) Semi-quantitative RT-PCR analysis of NTT, HEC1, and Kunitz-PI; 1 expression in 3-days old etiolated seedlings grown on ACC-containing, silver nitrate-containing or IAA-containing Murashige-Skoog medium. For comparison, actin transcript levels were assessed as internal standard. (B) Kunitz-PI;1 protein levels in 3-days old etiolated seedlings after growth on ACC-containing or $\mathrm{Ag}^{+}$-containing medium analyzed by Western blotting. (C) Kunitz-Pl;1 protein accumulation in etiolated seedlings of WT, ntt and hec1 mutant, as well as 35S::hec1 overexpressor. For SDS-PAGE (B,C), $40 \mu \mathrm{g}$ protein was loaded per lane and subjected to Western blotting using Kunitz-Pl;1-specific antibodies (upper panels); loading was confirmed by Ponceau-staining of the nitrocellulose-blotted proteins (lower panels). Note that the lower panels in (C) are composite diagrams. 